\section{COMPREHENSIVE TROPICAL MEDICINE TEXT}

Hunter's Tropical Medicine, Seventh Edition, Edited by G Thomas Strickland (1991). WB Saunders Company, 55 Horner Avenue, Toronto. Ontario M8Z 4X6. 1153 pages.

Why would I buy an expensive, heavy textbook about tropical mechicine? I can think of three good reasons: to help me with the diagnosis and treatment of a patient presenting with an unfaniliar constellation of symptoms - fever and unusual rash, or jaundice and cough - when I am working in a tropical setting: to provide me with comprehensive inlormation about all the exotic tropical diseases that are barely mentioned in standard medical texts; and to tell me which unfamiliar diseases I should be looking for in a sick patient who has recently arrived from a certain faraway land I know nothing about.

While reading through Hunter's Tropical Medicine I asked myself if the text satisfied the three good reasons for finding room for it on my overerowded bookshelf. And the answer was yes, this is a useful textbook.
The first part of the book discusses 'Clinical Practice in the Tropics' in 14 chapters. It is well-organized, makes effective use of tables and maps, and suggests investigations and treatments that are appropriate to Third World settings. For example, there is a very good discussion about rheumatic fever in which the emphasis is on clinical diagnosis rather than ECG or laboratory tests, and echocardiography is not mentioned. In a discussion of the treatment of meningitis. the virtues of chloramphenicol are highlighted while the expensive third generation cephalosporins arc mentioned only in passing. There are even some unexpected but useful instructions such as how to make cryoprecipitate in an ordinary refrigerator!

The next section of the text is the most extensive. covering all manner of infections, malignant diseases, poisonous plants and animals, and nutritional deficiencies. The topics and pathogens are organized into natural groupings that make them easy to find. despite the fact that they are discussed over the spread of 1000 pages. The photographs are numerous and of high quality. The writing is lucid.

Continued on page 149 
Continued from page 146

What intrigued me about this book was the 'Gazetteer of the Regional Distribution of Infectious Disease' in the final section entitled Tropical Disease in a Temperate Climate'. When I stumbled upon the Gazetteer - it was not advertised in the Table of Contents - I hoped I had found a user-friendly guide that told me which diseases to consider in a traveller arriving from a specific country. Unfortunately, what I found was comprehensive but not user-friendly. Yes, the information was all there... but the typeface highlighted the diseases instead of the countries, and the information was presented in dreary paragraphs rather than eyecatching tables. The editors had forgotten that the most definite information the travelling patient can tell the doctor is the travel itinerary - geography should have been the focal point of the Gazetteer. I will still refer to the Gazetteer, but hope that in the next edition it will bc easier to use.

Overall, this is an excellent book. Its practical advice to physicians in the field, its extensive use of tables and photographs, and its excellent chapters on fever, diarrhea and cosinophilia in the returning traveller make it far more than an encyclopedia of imported pathogens. It is a text that should have broad appeal... from ivory towers to ivory shores.

Ross A Pennie. MD, FRCPC Associate Professor of Pathology and Paediatrics Faculty of Health Sciences McMaster University 


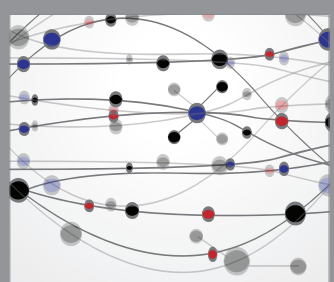

The Scientific World Journal
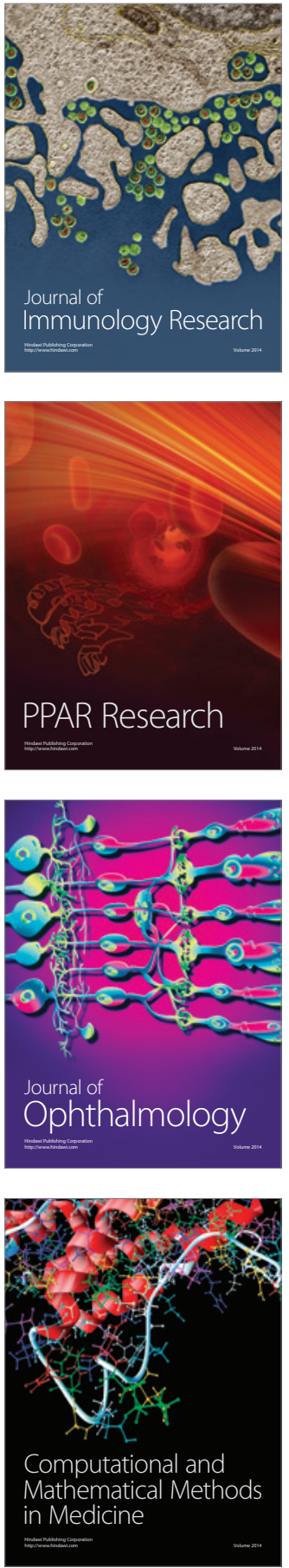

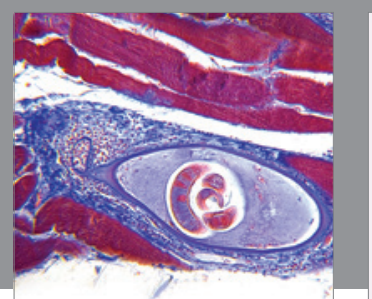

Gastroenterology Research and Practice

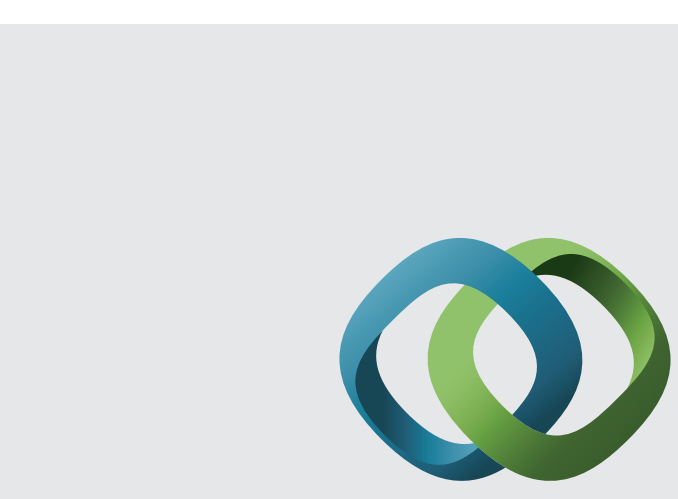

\section{Hindawi}

Submit your manuscripts at

http://www.hindawi.com
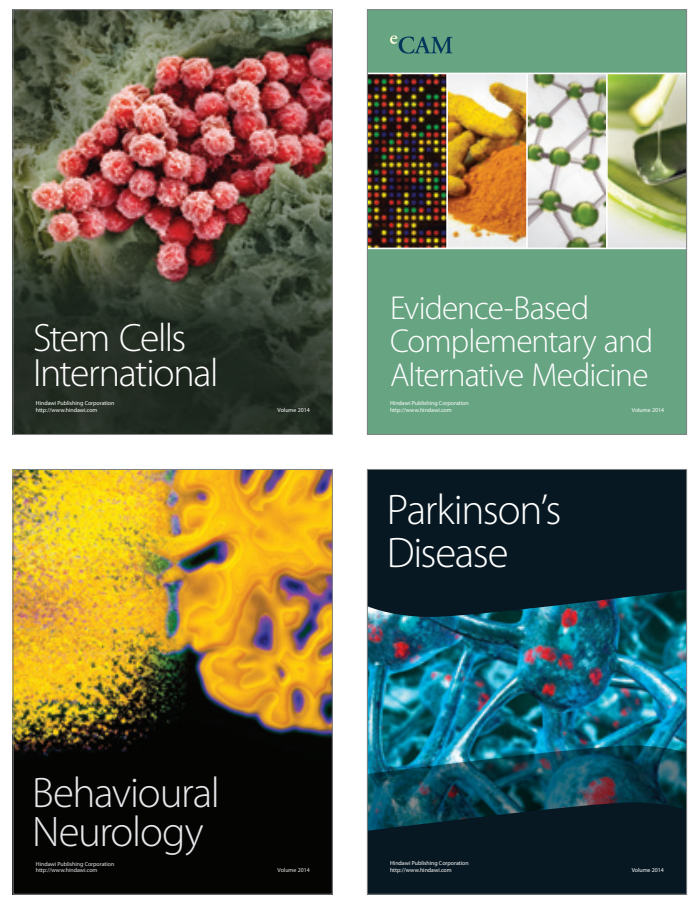
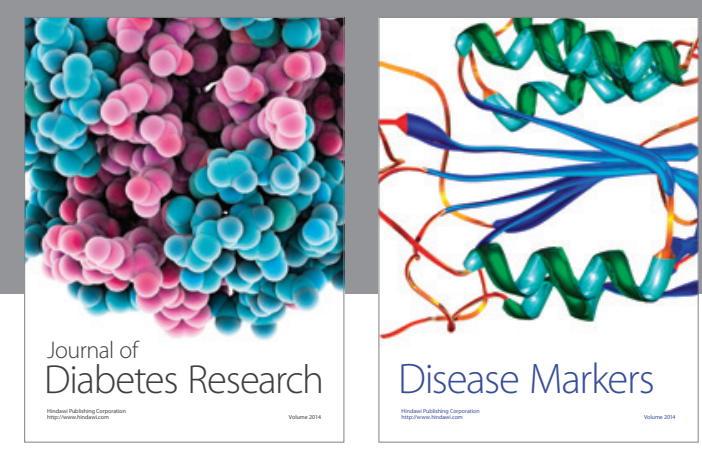

Disease Markers
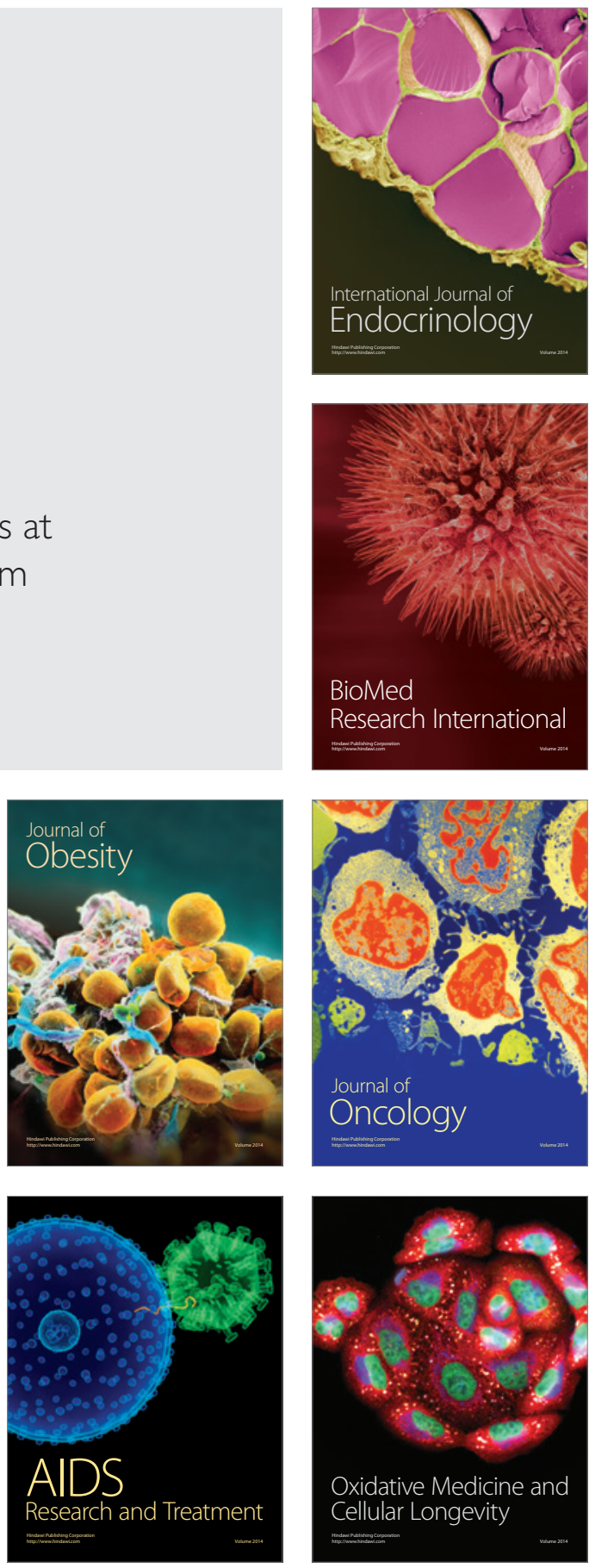